Document downloaded from:

http://hdl.handle.net/10251/164234

This paper must be cited as:

Sarmiento-Delgado, F.; Clairand, J.; Guerra-Terán, P.; Escrivá-Escrivá, G. (2019). Electric Vehicle Charging Load Prediction for Private Cars and Taxis Based on Vehicle Usage Data. IEEE. 1-6. https://doi.org/10.1109/CHILECON47746.2019.8988007

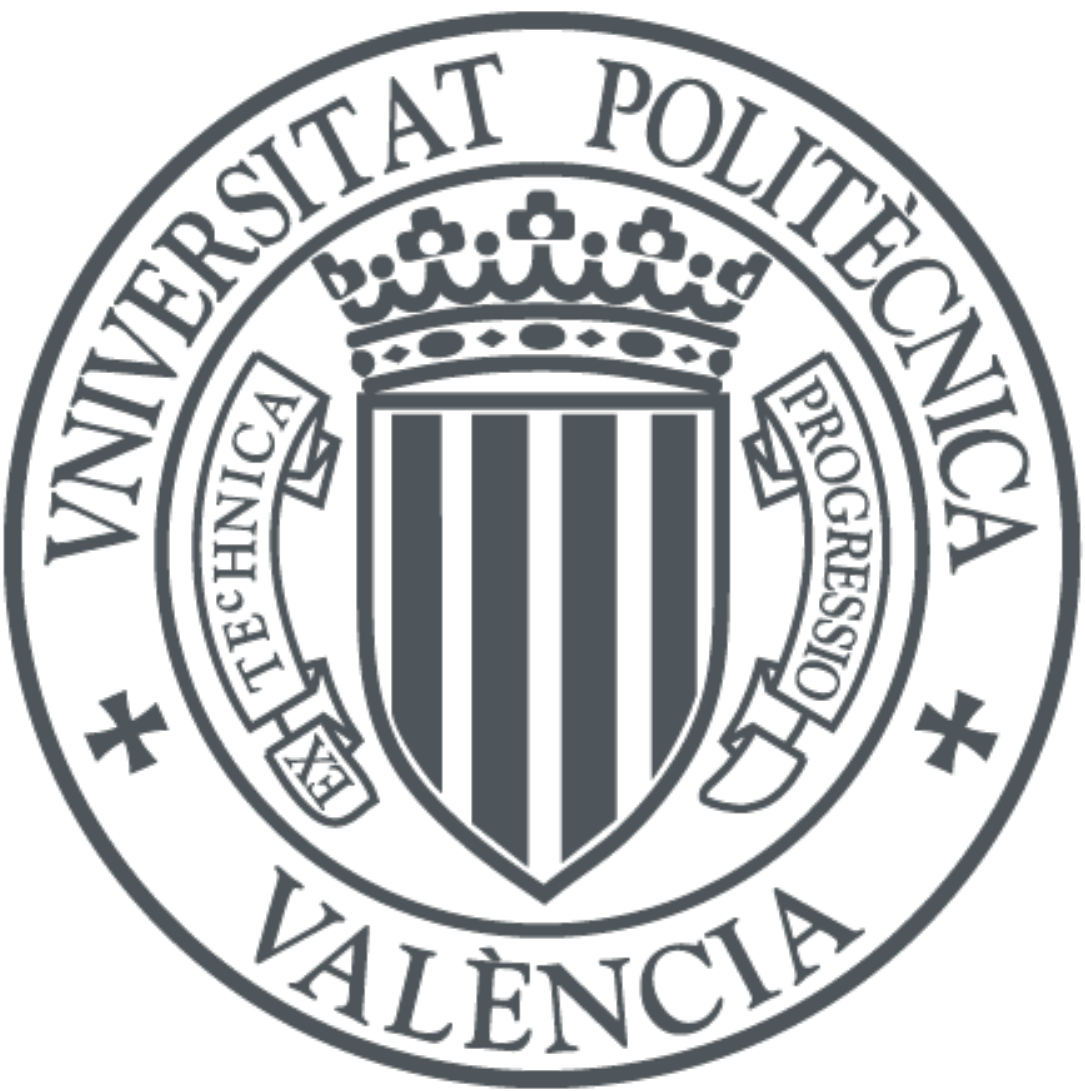

The final publication is available at

https://doi.org/10.1109/CHILECON47746.2019.8988007

Copyright IEEE

Additional Information 


\section{Electric Vehicle Charging Load Prediction for Private Cars and Taxis Based on Vehicle Usage Data}

\author{
Felipe Sarmiento-Delgado, \\ Jean-Michel Clairand, Member, IEEE, Paulo Guerra-Terán \\ Facultad de Ingenería y Ciencias Agropecuarias \\ Universidad de las Américas \\ 170122, Quito, Ecuador \\ E-mail: servio.sarmiento@udla.edu.ec, \\ jean.clairand@udla.edu.ec, paulo.guerra.teran@udla.edu.ec
}

\author{
Guillermo Escrivá-Escrivá \\ Institute for Energy Engineering \\ Universitat Politècnica de València \\ 46022, Valencia, Spain \\ E-mail: guieses@die.upv.es
}

\begin{abstract}
Electric Vehicles (EVs) are growing attention for their higher efficiency and less-polluting specifications. However, a massive introduction of EVs could lead to several issues in power systems. Several authors have proposed various smart charging approaches. But, these approaches could not be appropriately implemented without knowing the charging behavior of the EV customers. Thus, this paper proposes an EV charging load prediction for the particular case of Quito, Ecuador. This forecasting is performed based on data obtained from a GPS system and on statistical methods.

Keywords-Charging load prediction, Electric Vehicle, Monte Carlo Simulation, Smart Grid, Statistic Methods
\end{abstract}

\section{NOMENCLATURE}

\section{Indices}

$\begin{array}{ll}i & \text { vehicle index } \\ j & \text { day index } \\ k & \text { time interval index }\end{array}$

\section{Parameters}

$\eta_{E V} \quad$ EV efficiency $[\mathrm{km} / \mathrm{kWh}]$

$C \quad$ battery capacity $[\mathrm{kWh}]$

$N \quad$ Number of EVs

$P^{c h} \quad$ Charging power rate $[\mathrm{kW}]$

$P_{k, i} \quad$ EV load of EV $i$ at time interval $k$ [kW]

$S O C^{A} \quad$ State-of-charge when arriving home [\%]

$t^{\text {dep }} \quad$ home departure time $[\mathrm{h}]$

Sets

$S_{j} \quad$ Time intervals in a day $j$

\section{Variables}

$P_{k}^{E V} \quad$ Total EV load at time interval $k[\mathrm{~kW}]$

$S O C^{D}$ State-of-charge when departing home [\%]

$t^{\text {end }} \quad$ Charging end time $[\mathrm{h}]$

\section{INTRODUCTION}

Electric Vehicles (EVs) are considered an effective transportation technology for reducing greenhouse gas emissions and local pollution in the cities, which is mainly generated by internal combustion vehicles. Several governments have implemented initiatives for promoting the purchase of EVs for private customers, and public transportation, such as buses and taxis. However, a massive introduction of EVs could lead to issues and challenges for the power grid, including voltage drops [1], significant distribution investments [2], and power losses [3]. Hence, the distribution network hosting capacity needs to be evaluated to guarantee correct grid constraints [4].

In the future Smart Grid, EV users, instead of passive consumers, will become active prosumers who can provide power and energy services to electric utilities, such as ancillary services [5]. For this, it is necessary to know the behavior of users for charging their EVs.

EV data are scarce, so various projects were developed in the world to understand how people charge their EVs, such as the MEA project [6]. However, these projects result expensive and they allow to understand the charging habits of particular customers of a place. The habits of customers vary depending on countries or cities.

Some barriers exist in Latin American countries, which have limited a larger adoption such as some countries in Europe and Asia, and in the USA, including the lack of effective subsidies from he governments for EVs, insufficient charging infrastructure, and important subsidies in fossil fuels [7]. Although these barriers, in Ecuador, like many Latin American countries, it is expected that the numbers of EVs will increase significantly next years. Thus, a proper estimation to the EV charging load is necessary considering local users behavior.

It becomes crucial to alleviate the impacts of EVs on power systems. Thus, several authors have studied solutions to appropriately manage this new load. These solutions include peak reductions, cost reductions, power losses reductions, among others. For this, smart charging approaches are considered, which consider energy management for charging the EVs [8][10]. Moreover, EVs can even improve grid system by proving services to the grid, such as ancillary services [11]. Other studies focus on the impact of EVs in systems with high penetration of renewable energy [12]-[14].

Although these studies and others demonstrate their effectiveness on the grid, they are mostly based on assumed information on the EV load. To be effective, realistic EV charging profiles must be required. Hence, other researchers have studied the EV charging load profiles, using deterministic and stochastic approaches.

To forecast EV load, the behavior of the EV customers need 
to be studied. Some important variables that are considered in the various models include the arrival time, the departure time, the distance driven. These variables allow to model EV characteristics such as the starting charging time, the end time of charging, the state-of-charge (SOC), the power and energy required. In [15], a Monte Carlo simulation is used to forecast charging load by classifying the types of plug-in EVs, charging time, ways to complete the energy supply of plug-in EVs in China. The authors of [16] propose a non-parametric Gaussian kernel density estimation method, demonstrating that is more efficient than Monte Carlo Simulation. In [17], a statistical methodology is presented, using real-data to obtain plug-in and hybrid EV load profiles. The authors of [18] study a stochastic model using the US national household travel survey to obtain the plug-in EV profiles. In [19], a comprehensive probabilistic model is built considering data of UK.

However, these works and others use data from surveys, which could not be very realistic. To overcome this drawback, some authors employ real-world electric vehicle charging data. For example, in [20], stochastic simulation is proposed considering GPS travel data collected during an EV demonstration trial. The authors of [21] investigate a regression method considering datasets provided by the municipality of Amsterdam of an EV project. In [22] evaluates the effects of social characteristics of EV drivers using an agent-based approach by NetLogo software and considering data sets from Singapur. By the other hand, other researchers perform the forecasting based on the information of battery chargers, as per [23], where the modeling of battery chargers is studied to obtain the charging patterns. Despite this, in [24], it is shown that customer profile based prediction is faster than station measurement, considering similar0 forecasting errors.

Just a few works have investigated the travel patterns of drivers, by using GPS systems, such as [20], [25]. Driving behavior is very different from one place to another, especially due to different schedule work conditions, so it is necessary to evaluate specific behavior for a case study. Moreover, these works correspond only to private cars and no work has predicted the future charging load of electric taxis. The aim of this paper is to obtain an EV charging profile prediction for the case of Quito, Ecuador, for both private cars and taxis.

The rest of this paper is organized as follows. Section II proposes the Prediction methodology. Section III presents the case study. Section IV discusses the results. Finally, Section V highlights the main conclusions and contributions of the paper.

\section{Prediction methodology}

\section{A. Data collection by GPS}

To obtain the data, the GPS device is installed in the vehicle and the information is collected during the 5 working days, which is considered the appropriate period to evaluate the critical load. The data obtained is the date, hour, latitude, longitude, speed, driven distance, and location.

The GPS used for the present project is the GL300 model. This device was chosen for features and algorithms that make it water resistant, have 3 axes for the integrated speedometer

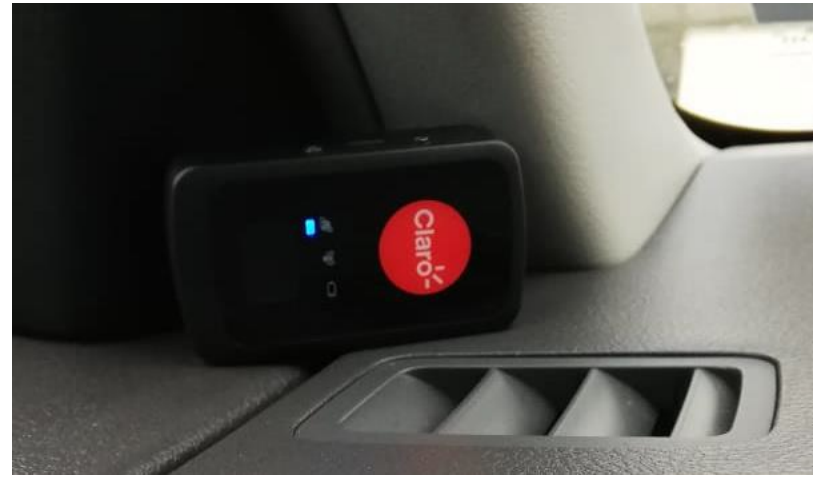

Fig. 1. GPS system in a vehicle.

and extreme battery life, as well as having a web platform which shows administrators the location of the device. Fig. 1 depicts the GPS systems installed in a vehicle.

The Web platform used for the research project was provided by the company CLARO, since it is the only one legally authorized to control the GL300 GPS monitoring. This Web platform can make queries to monitor the GPS activity, that is, it can create reports of all the events that have happened with the GPS user. To identify the events and classify them, the Web platform provides activity graphs, and relevant data such as distance traveled, maximum / minimum speed, latitude and longitude of the user.

The Date and Time columns are used to represent the day and time of the user's positioning. The hour column is crucial during the deterministic model, since it allows determining when the user leave home and stop using his vehicle. The Latitude, Longitude and Direction columns will help to determine the possible charging stations using a density diagram using Google Earth software. Finally, the odometer of the GPS device, marks the distance traveled by the user, which helps us to obtain the input data of the deterministic model.

Between 2800 to 5500 daily sequence points are obtained in each of the private vehicles with a total of 131706 points counting for 27 private vehicles. Moreover, a total of 93699 sequence points in 10 taxi cars were obtained. These data sets were filtered since several errors were obtained, due especially to stops in lights.

\section{B. Statistical methodology}

Some assumptions are firstly made:

- To comply with the specification of the model, it is assumed that the EV will be charged only at home immediately after the end time of use of the vehicle.

- The EV starts working with its SOC at $100 \%$.

- The maximum charging power rate is assumed to be 6.6 $\mathrm{kW}$.

It was focused in the data collection on the departure time, arrival, maximum speed, and distance traveled from the vehicle. 
To obtain the electricity needed, the $S O C$ is calculated for each user. The next equation is used as per [25]:

$$
S O C_{i, j}^{A}=S O C_{i, j}^{D}-\frac{t_{i, j}^{d e p}}{\eta_{E V} \cdot C} \cdot 100
$$

Then the end charging time is defined:

$$
t_{i, j}^{e n d}=\frac{P^{c h} \cdot d_{i, j}}{\eta_{E V}}
$$

To obtain the required energy, the following equation is used:

$$
E_{i, j}^{r e q}=\frac{d_{i, j}}{\eta_{E V}}
$$

Then, the charging duration is defined:

$$
T_{i, j}=\frac{E_{i, j}^{r e q}}{P^{c h}}
$$

The set of time intervals $S_{j}$ in a day $j$ is:

$$
S_{j}=\{1,2, . ., D\}
$$

To obtain the charging load profile, it is necessary to calculate the total power consumed by all the EVs, which is the sum of the power of each EV $i$ at each time interval $k$, as defined as follows:

$$
P_{k}=\sum_{i=1}^{N} P_{k, i}, \forall k \in S_{j}
$$

\section{CASE Study}

\section{A. Quito - Ecuador}

The case study of Quito, Ecuador was selected to forecast the EV charging load prediction. This case study was selected based on the willingness of the major of Quito to incentive the purchase of EVs for public and private transportation [26]. Quito is the capital of Ecuador, with an elevation of 2,800 meters above sea level. This is another reason to push to this greener alternative because in high altitudes the efficiency of internal combustion vehicles decrease and more polluting gases are emitted. The map of Quito is depicted in Fig. 2. Quito has a population of 2.6 million inhabitants and the last survey indicates that Quito has 382,314 vehicles.

For the case study, two particular segments of vehicles are evaluated. The private cars that belong to typical users that go from home to work and inversely each day. The other segment corresponds to taxi drivers, which are considered public transportation. The buses could not be evaluated due to impediments of the companies.

\section{B. Input Data}

The considered EV for the EV load modeling is the Kia Soul. Based on the data sheet the charging power rate $P^{c h}$ was assumed to be constant and to be $6.6 \mathrm{~kW}$.

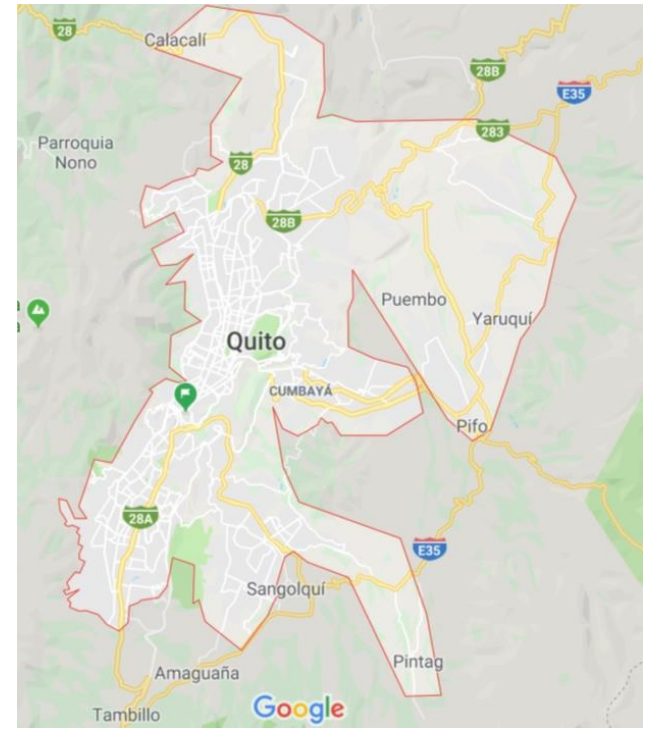

Fig. 2. Map of Quito.

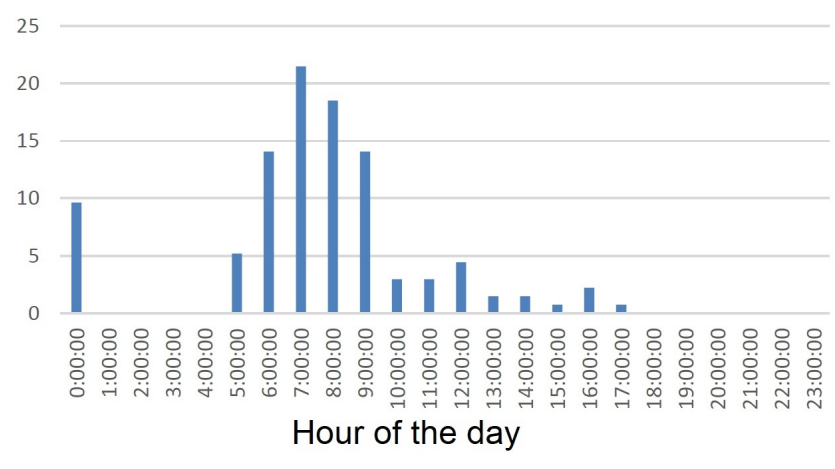

Fig. 3. Range frequency of the departure time in a day.

\section{RESULTS}

\section{A. Private Cars Behavior Analysis}

Firstly, the departure time and home arrival are organized by range frequencies in the different hours of the day, as depicted in Fig. 3 and Fig 4 respectively. Observe that most of the drivers depart home between 6 AM to 9AM, and arrive home between 4 PM to 8PM.

Then, the daily driven distance is filtered. In Fig. 5, the frequency of daily distance driven for taxis is illustrated. Note that most of the customers drive between 40 to $60 \mathrm{~km}$.

\section{B. Taxi Cars Behavior Analysis}

In Fig. 6 and Fig. 7, the range frequency of travel departures and travel end respectively of taxis are represented. Note that the departures are considerable during all day and the travel end correspond to the beginning of the afternoon to the beginning of the night.

Then, the driven distance of the taxis is obtained and depicted in Fig. 8. Observe that the driven distance is much 


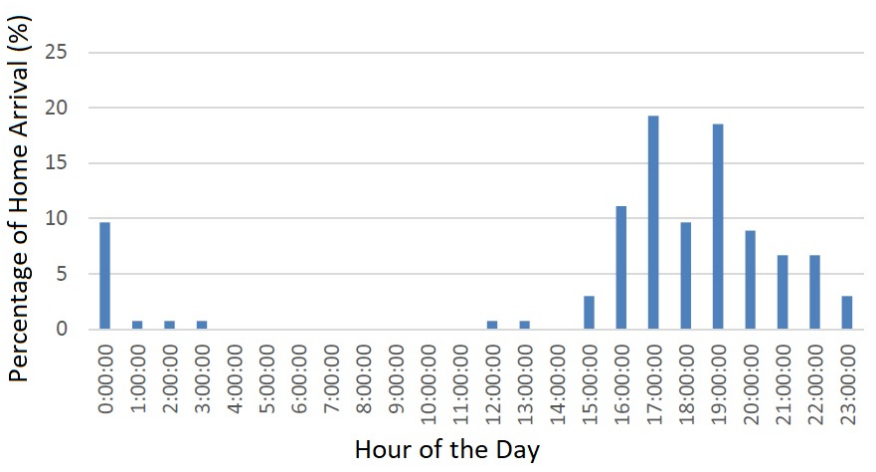

Fig. 4. Range frequency of the home arrival in a day.

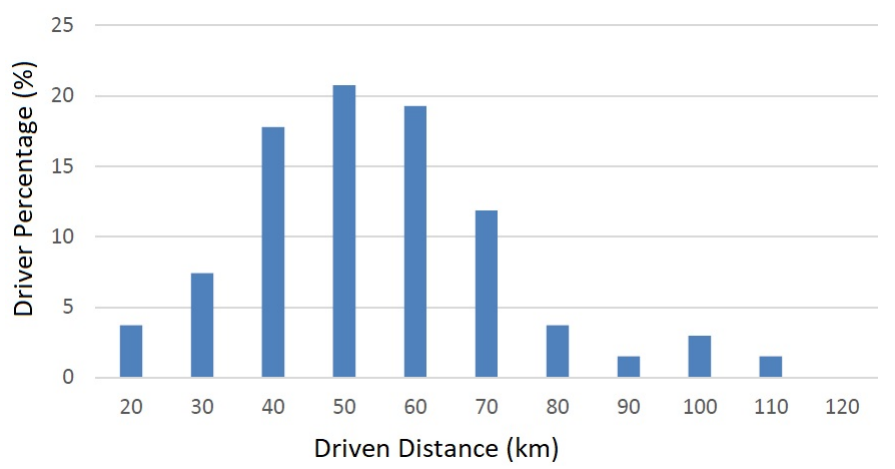

Fig. 5. Frequency of distance driven for taxis.

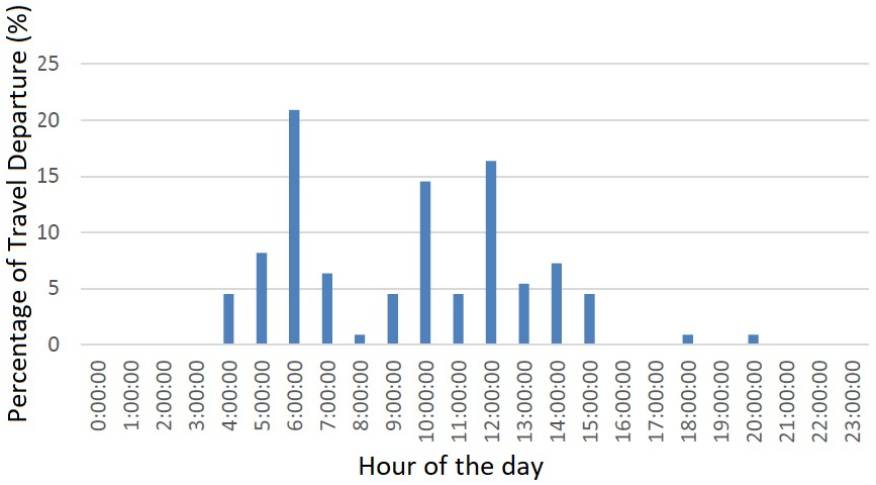

Fig. 6. Range frequency of the departure time in a day.

bigger than the private cars, which was clearly expected. Many of the taxis drive more than $170 \mathrm{~km}$, so a change from internal combustion vehicles to EVs would lead to a significant load increase.

\section{Energy Analysis}

A Monte Carlo simulation is performed in order to obtain a sensitivity analysis of the variations of the required energy. The selected number of simulations was 382,314 for the private cars that correspond to the actual number of vehicles in Quito. Fig. 9 illustrates the required energy by number of users for

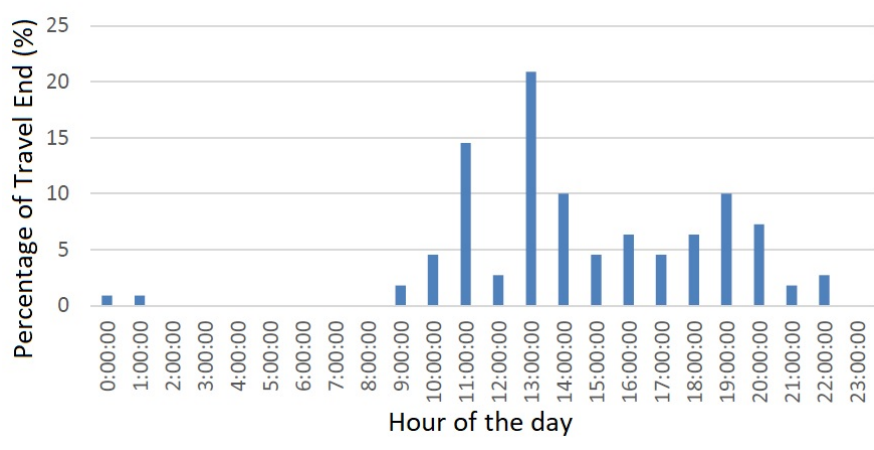

Fig. 7. Range frequency of the home arrival in a day.

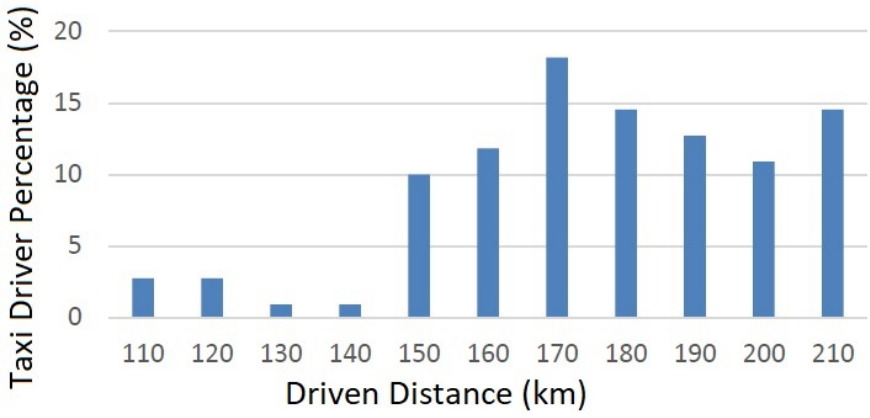

Fig. 8. Range frequency of the home arrival in a day.

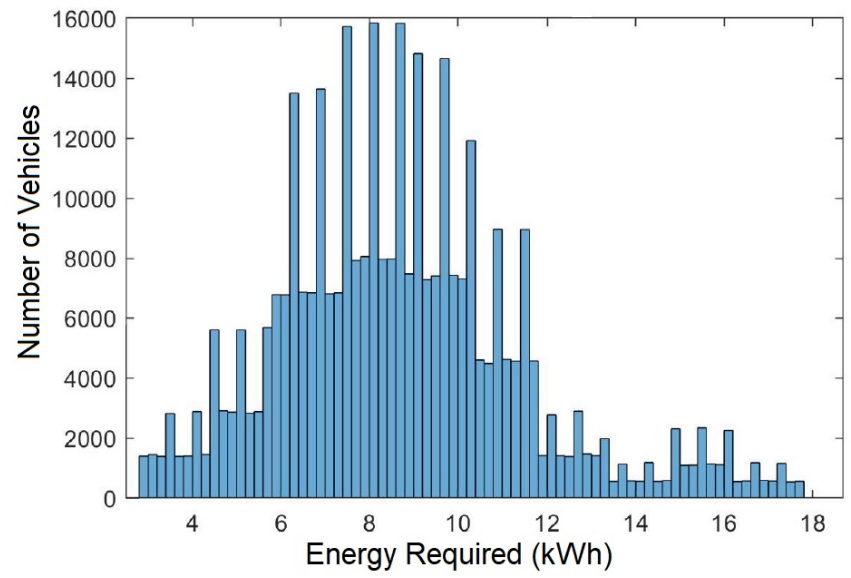

Fig. 9. Energy required for private cars by number of users.

private cars. It should be noted that most of the future EV users could require between 6 to $12 \mathrm{kWh}$ per day.

For the taxis, a Monte Carlo simulation was performed too, considering 16,024 simulations, which corresponds to the number of actual taxis in Quito. Fig. 10 illustrates the required energy by number of users for taxis. Observe that the number of vehicles is much smaller but the required energy is between 26 to $40 \mathrm{kWh}$, which is more than 3 times the energy required for private vehicles. 


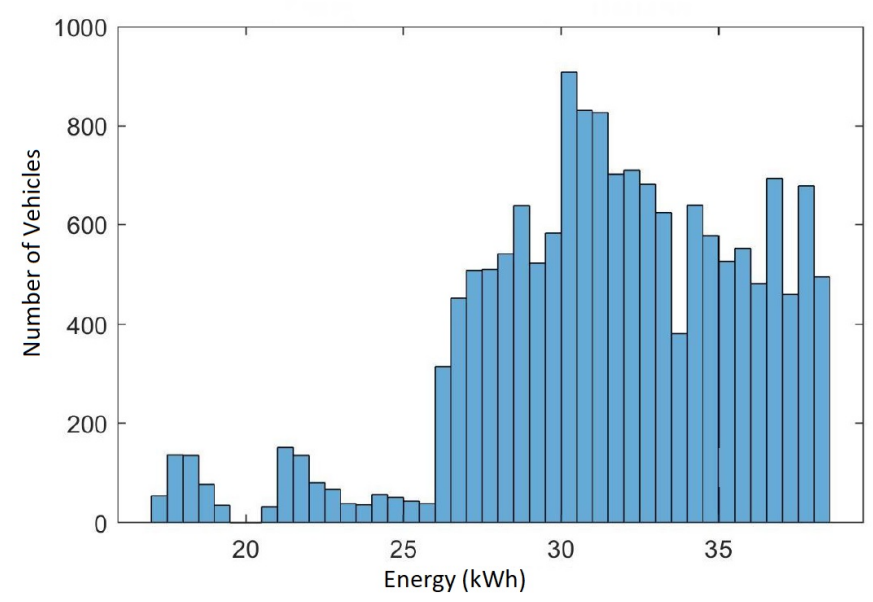

Fig. 10. Energy required for taxis by number of users.

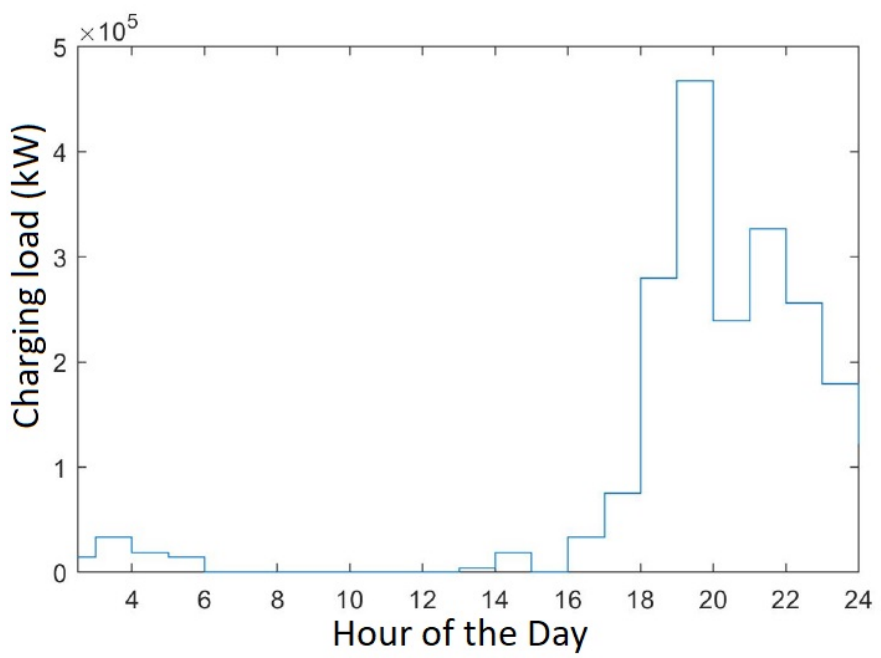

Fig. 11. Charging load for private EVs.

\section{EV Charging Load}

In Fig. 11 the EV load corresponding to the private cars is represented. Significant peaks are observed starting 6PM, which is generally an hour when typical electricity peaks already exists. Therefore, this additional load has to be adequately managed in order to mitigate grid issues.

Fig. 12 represents the Ev load corresponding to the taxis. Note that a peak is observed at 4PM and 7PM and significant load is observed during all night. The peak load of 7PM could be managed to be reduced, but the load in the other hours could not lead to issues in the grid, especially because of the low electricity demand during the night.

\section{CONCLUSIONS}

In this paper, the EV charging load prediction for both private and taxis EVs is studied. This prediction was performed through real-data acquisition from a GPS system tat was installed in several internal combustion vehicles, to analyze the driving behavior of the different customers. Then, a statistical

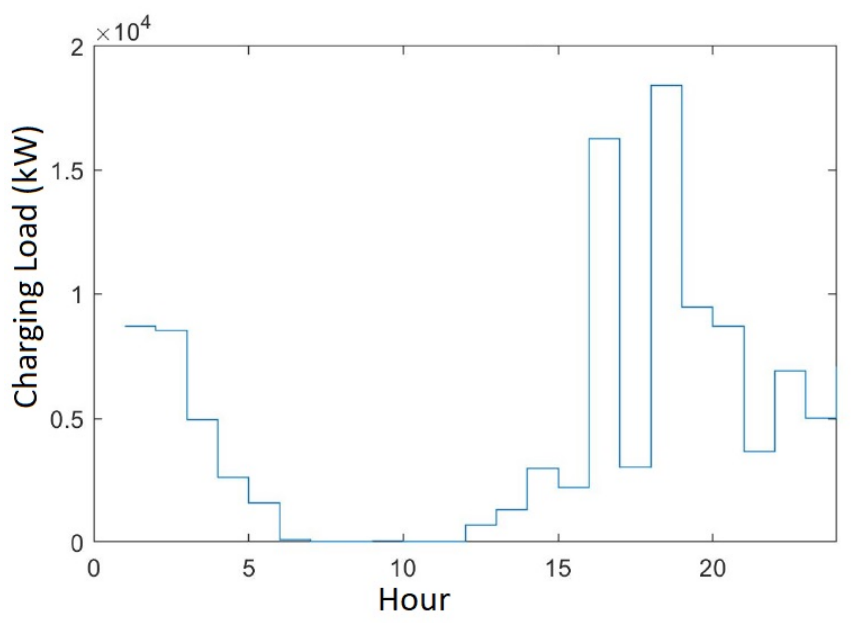

Fig. 12. Charging load for Taxi EVs.

method is proposed to predict different crucial variables for load prediction, such as departure and arrival hours, and drive distance. The predicted EV charging load is obtained, based on the predicted energy required and the analyzed variables.

The case study of Quito, Ecuador is analyzed. The results indicate that significant peaks are observed during the night for private cars, which can lead to grid issues if several EVs are purchased in the case study. Therefore, it is necessary to adopt proper charging strategies.

\section{ACKNOWLEDGEMENTS}

This work belongs to project SIS.JCG.19.03 of Universidad de las Américas - Ecuador.

\section{REFERENCES}

[1] K. Clement-Nyns, E. Haesen, and J. Driesen, "The impact of Charging plug-in hybrid electric vehicles on a residential distribution grid," IEEE Trans. Power Syst., 2010.

[2] L. Pieltain Fernández, T. Gómez San Román, R. Cossent, C. Mateo Domingo, and P. Frías, "Assessment of the impact of plug-in electric vehicles on distribution networks," IEEE Trans. Power Syst., 2011.

[3] S. Shafiee, M. Fotuhi-Firuzabad, and M. Rastegar, "Investigating the impacts of plug-in hybrid electric vehicles on power distribution systems," IEEE Trans. Smart Grid, vol. 4, no. 3, pp. 1351-1360, 2013.

[4] J. Zhao, J. Wang, Z. Xu, C. Wang, C. Wan, and C. Chen, "Distribution Network Electric Vehicle Hosting Capacity Maximization: A Chargeable Region Optimization Model," IEEE Trans. Power Syst., vol. 32, no. 5, pp. 4119-4130, 2017.

[5] G. Strbac, D. Pudjianto, M. Aunedi, D. Papadaskalopoulos, P. Djapic, Y. Ye, R. Moreira, H. Karimi, and Y. Fan, "Cost-effective decarbonization in a decentralized market: The benefits of using flexible technologies and resources," IEEE Power Energy Mag., vol. 17, no. 2, pp. 25-36, 2019.

[6] J. Quirós-Tortós, L. N. Ochoa, and T. Butler, "How Electric Vehicles and the Grid Work Together," IEEE Power Energy Mag., no. October 2018, pp. 64-76, 2018.

[7] J. Quiros-Tortos, L. Victor-Gallardo, and L. Ochoa, "Electric Vehicles in Latin America: Slowly but Surely Toward a Clean Transport," IEEE Electrif. Mag., vol. 7, no. 2, pp. 22-32, 2019. [Online]. Available: https://ieeexplore.iee.org/document/8732487/

[8] I. Sharma, K. Bhattacharya, C. Canizares, and K. Bhattacharya, "Smart Charging of PEVs Penetrating Into Residential Distribution Systems," IEEE Trans. Smart Grid, vol. 5, no. 3, pp. 1196-1209, 2014. 
[9] E. Karfopoulos and N. Hatziargyriou, "Distributed coordination of electric vehicles for conforming to an energy schedule," Electr Power Syst. Res., vol. 151, pp. 86-95, 2017. [Online]. Available: http://dx.doi.org/10.1016/j.epsr.2017.05.018

[10] J.-M. Clairand, J. Rodríguez-García, and C. Álvarez-Bel, "Smart Charging for Electric Vehicle Aggregators considering Users' Preferences," IEEE Access, vol. 6, pp. 1-12, 2018.

[11] C. Le Floch, E. Kara, and S. Moura, "PDE Modeling and Control of Electric Vehicle Fleets for Ancillary Services: A Discrete Charging Case," IEEE Trans. Smart Grid, vol. 9, no. 2, pp. 1-1, 2016. [Online]. Available: http://ieeexplore.ieee.org/document/7457320/

[12] P. Vithayasrichareon, G. Mills, and I. F. Macgill, "Impact of electric vehicles and solar pv on future generation portfolio investment," IEEE Trans. Sustain. Energy, vol. 6, no. 3, pp. 899-908, 2015.

[13] H. Yang, H. Pan, F. Luo, J. Qiu, Y. Deng, M. Lai, and Z. Y. Dong, "Operational Planning of Electric Vehicles for Balancing Wind Power and Load Fluctuations in a Microgrid," IEEE Trans. Sustain. Energy, vol. 8, no. 2, pp. 592-604, 2017.

[14] J.-M. Clairand, J. Rodríguez-García, and C. Álvarez-Bel, "Electric Vehicle Charging Strategy for Isolated Systems with High Penetration of Renewable Generation," Energies, vol. 11, no. 11, pp. 1-21, 2018.

[15] Z. Luo, Y. Song, Z. Hu, Z. Xu, X. Yang, and K. Zhan, "Forecasting charging load of plug-in electric vehicles in China," IEEE Power Energy Soc. Gen. Meet., pp. 1-8, 2011.

[16] M. Liang, W. Li, J. Yu, and L. Shi, "Kernel-based electric vehicle charging load modeling with improved Latin hypercube sampling," IEEE Power Energy Soc. Gen. Meet., vol. 2015-Septe, pp. 1-5, 2015.

[17] Z. Darabi, S. Member, and M. Ferdowsi, "Aggregated Impact of Plug-in Hybrid Electric Vehicles on Electricity Demand Profile," IEEE Trans. Sustain. Energy, vol. 2, no. 4, pp. 501-508, 2011.

[18] N. H. Tehrani and P. Wang, "Probabilistic estimation of plugin electric vehicles charging load profile," Electr. Power Syst. Res., vol. 124, pp. 133-143, 2015. [Online]. Available: http: //dx.doi.org/10.1016/j.epsr.2015.03.010

[19] Q. Hu, H. Li, and $\mathrm{S}$. Bu, "The prediction of electric vehicles load profiles considering stochastic charging and discharging behavior and their impact assessment on a real UK distribution network," Energy Procedia, vol. 158, pp. 6458-6465, 2019. [Online]. Available: https://doi.org/10.1016/j.egypro.2019.01.134

[20] J. Brady and M. O'Mahony, "Modelling charging profiles of electric vehicles based on real-world electric vehicle charging data," Sustain. Cities Soc., vol. 26, pp. 203-216, 2016. [Online]. Available: http://dx.doi.org/10.1016/j.scs.2016.06.014

[21] J. J. Mies, J. R. Helmus, and R. van den Hoed, "Estimating the charging profile of individual charge sessions of Electric Vehicles in The Netherlands," World Electr. Veh. J., vol. 9, no. 2, 2018.

[22] K. Chaudhari, N. K. Kandasamy, A. Krishnan, A. Ukil, and H. B. Gooi, "Agent-based aggregated behavior modeling for electric vehicle charging load," IEEE Trans. Ind. Informatics, vol. 15, no. 2, pp. 856-868, 2019.

[23] A. M. A. Haidar, K. M. Muttaqi, and S. Member, "Behavioral Characterization of Electric Vehicle Charging Loads in a Distribution Power Grid Through Modeling of Battery Chargers," IEEE Trans. Ind. Appl., vol. 52, no. 1, pp. 483-492, 2016.

[24] M. Majidpour, C. Qiu, P. Chu, H. R. Pota, and R. Gadh, "Forecasting the EV charging load based on customer profile or station measurement?" Appl. Energy, vol. 163, pp. 134-141, 2016. [Online]. Available: http://dx.doi.org/10.1016/j.apenergy.2015.10.184

[25] A. Ashtari, E. Bibeau, S. Shahidinejad, and T. Molinski, "PEV charging profile prediction and analysis based on vehicle usage data," IEEE Trans. Smart Grid, 2012.

[26] PublicaFM, "Yunda quiere autos eléctricos para Quito." [Online]. Available: https://www.publicafm.ec/noticias/actualidad/1/ alcalde-transporte-electrico-quito 